\title{
A Educação Ambiental frente aos desafios apresentados pelos discursos contemporâneos sobre a natureza*
}

Marcos Reigota

Universidade de Sorocaba

Correspondência:

Marcos Reigota

Av. Dr. Eugênio Salerno, 140

18035-430 - Sorocaba - SP

E-mail:marcos.reigota@prof.uniso.br

\section{Resumo}

A noção de natureza tem tido papel importante na filosofia e também na Educação Ambiental. Filósofos contemporâneos como Gianni Vattimo e Newton Aquiles von Zuben afırmam que uma noção única de natureza contribuiu para a difusão da metafísica dogmática, que por sua vez, solidificou totalitarismos políticos e religiosos. A Educação Ambiental latino-americana tem constituído um campo teórico e espaço público privilegiado para a difusão de noções de natureza, não dogmáticas, nem totalitárias, em estreitas relações com a diversidade cultural e social. Num primeiro momento da Educação Ambiental a noção de natureza estava relacionada aos recursos naturais. Desde que temas específicos relacionados com os discursos contemporâneos sobre a natureza, como a biodiversidade e os transgênicos ganharam o espaço público, argumentamos que a Educação Ambiental se viu diante de novos desafios teóricos, políticos, ecológicos, sociais, culturais e pedagógicos. Neste artigo procuramos identificar e analisar alguns desses desafios tendo como apoio teórico o pensamento do filósofo italiano Gianni Vattimo e do filósofo brasileiro Newton Aquiles von Zuben, nos aspectos relacionados à bioética e ao papel político da educação, na formação de cidadãos e cidadãs. Concluímos que a abordagem dos discursos contemporâneos sobre a natureza possibilita que o diálogo entre a Educação Ambiental e a bioética tende a se ampliar e a se concretizar em práticas sociais e pedagógicas cotidianas, apresentando-se, assim, como alternativa concreta para que cidadãos e cidadãs possam enfrentar os desafios trazidos com a biodiversidade e com os transgênicos, com argumentos científicos, éticos e políticos.

\section{Palavras-chave}

Natureza - Biodiversidade - Transgênicos - Educação Ambiental Bioética. 


\title{
Environmental Education and the challenges presented by the contemporary discourses about nature ${ }^{\star}$
}

\author{
Marcos Reigota \\ Universidade de Sorocaba
}

Contact:

Marcos Reigota

Av. Dr. Eugênio Salerno, 140

18035-430 - Sorocaba - SP

E-mail: marcos.reigota@prof.uniso.br

\begin{abstract}
The notion of nature has played an important role in philosophy and also in Environmental Education. Contemporary philosophers such as Gianni Vattimo and Newton Aquiles von Zuben declare that the notion of a single nature has contributed to the growth of a dogmatic metaphysics that has crystallized political and religious totalitarianisms. Environmental Education in Latin America has constituted a theoretical field and a privileged public space for the diffusion of non-dogmatic, non-totalitarian, notions of nature in close relationship to cultural and social diversity. At a first moment of Environmental Education the notion of nature was linked to natural resources. However, after specific themes related to the contemporary discourses about nature, such as transgenetics and biodiversity, have gained the public sphere we argue that Environmental Education has been facing new theoretical, political, ecological, social, cultural and pedagogical challenges. In the present article we try to identify and analyze some of these challenges, having as our theoretical foundation the ideas of Italian thinker Gianni Vattimo, and of Brazilian philosopher Newton Aquiles von Zuben, on the aspects related to bioethics and to the political role of education in the formation of citizens. We conclude that the approach to nature present in contemporary discourses helps to open out the dialogue between Environmental Education and bioethics, and to materialize it in daily social and pedagogical practices, thus representing a concrete alternative to allow citizens to face up to the challenges brought about by biodiversity and the transgenics with scientific, ethical and political arguments.
\end{abstract}

\section{Keywords}

Nature - Biodiversity - Transgenics - Environmental Education Bioethics. 
queda de folhas

alegria passageira

de um pé de vento.

(Teruko Oda)

Abordar as dimensões filosóficas e políticas dos discursos contemporâneos sobre a natureza, enfocando a biodiversidade e os transgênicos nas suas relações com a Educação Ambiental, é uma tentativa de analisar e interferir no debate público e acadêmico que ultrapassa fronteiras locais e disciplinares. É também uma tentativa de (re)situar o papel e a pertinência da Educação Ambiental que se quer política, voltada para a participação dos cidadãos e cidadãs, tendo a cidadania e a ética como dois dos seus principais argumentos (cf. Pelicioni; Philippi Junior, 2007; Noal; Barcelos, 2003; Cascino; Jacobi; Oliveira, 1998; Rodrigues, 1997).

0 tema poderia ser discutido sobre vários aspectos e contribuições das ciências e artes, mas a opção pela filosofia contemporânea se dá pela importância que tanto a natureza como o que se convencionou chamar de tecnociências ocuparam ao longo da tradição filosófica moderna e o protagonismo a que chegaram no contexto do pensamento pós-moderno, entendido como "o mundo da mediatização total de nossa experiência” (Vattimo, 2002b, p. 189).

Filósofos como Gianni Vattimo e Newton Aquiles von Zuben ocupam papel de destaque nesse debate e é a partir dos argumentos deles que pretendemos desenvolver o nosso tentando responder a seguinte questão: como que os atuais discursos sobre a natureza que incluem a biodiversidade e os organismos geneticamente modificados (transgênicos) desafiam a Educação Ambiental?

0 italiano Gianni Vattimo se aposentou em 2008 como professor da Universidade de Turim. Ele escreveu obras traduzidas em várias línguas que o situam como um dos principais autores do pensamento pós-moderno.

Vattimo tem intensa atividade pública e política, escrevendo para jornais e participando de debates com e nos movimentos sociais. Ele foi deputado no Parlamento Europeu de 1999 a 2004, onde se destacou por defender os interesses dos grupos minoritários e marginalizados (cf. Vattimo, 2006b, Vattimo; Paterlini, 2006, Zabala, 2007).

Nas últimas duas décadas o Vaticano é uma das instituições que mais tem recebido as criticas de Vattimo, devido à sua política e a discursos dogmáticos sobre a vida e a morte (pautados em uma concepção metafísica de natureza), que impedem a elaboração de políticas públicas relacionadas, por exemplo, com a eutanásia, com o aborto e com a procriação in vitro (Vattimo, 2006a).

Nos anos 1990, o filósofo italiano se (re) converteu ao cristianismo (cf. Girard; Vattimo, 2009) e tem declarado-se publicamente como um filósofo católico, anarquista e comunista.

Em um dos seus livros mais recentes, publicado inicialmente em Cuba, enfatiza a sua opção política pelo comunismo. Utilizando-se do titulo de um dos mais conhecidos livros de Nietzsche (Ecce homo) intitula o seu de Ecce сотu (Vattimo, 2006b).

Em entrevista, quando esteve no Brasil em novembro de 2008, à revista Cult Vattimo (2008) declara:

Por mais que soe escandaloso me defino como comunista. 0 comunismo real - aquele de Stálin - caiu, e, portanto, pode-se de novo, ser comunista enquanto partidário de uma sociedade sem classes [...]. Não creio que o comunismo deva ser autoritário; penso que é indispensável uma certa quota de anarquismo para que ele se realize verdadeiramente. (p. 13-14)

Já foi observado que Gianni Vattimo é considerado um dos autores mais expressivos do pensamento pós-moderno, mas ele se diferencia de Jean-François Lyotard (que ficou conhecido como aquele que definiu o termo e inaugurou uma vertente teórica nas ciências humanas). Segundo Vattimo (2002a), a sua diferença em relação ao pensamento de Lyotard ocorre

[...] pela necessidade de afirmar que a passagem ao pós-moderno indica uma direção: 
da unidade forte à multiplicidade frágil, do domínio à liberdade, do autoritarismo à democracia. ${ }^{1}$ (p. 66)

Ao se (re)converter ao cristianismo trouxe ao debate pós-moderno a importância política e existencial da religiosidade dialogando com, entre outros, Jacques Derrida (Derrida; Vattimo, 2000), Richard Rorty (Rorty; Vattimo, 2005) e René Girard (Girad; Vattimo, 2009).

A sua (re)conversão pública ao cristianismo foi acompanhada da desobediência e enfrentamento dos dogmas defendidos e difundidos pela hierarquia eclesiástica católica. Entre várias justificativas nos depoimentos e entrevistas que deu, conferências que proferiu e textos que escreveu sobre a sua mais recente opção teórica, política e religiosa, afirmou que “A encarnação de Deus é também um evento de fragilização, na qual Deus se abaixa e perde o tratamento que lhe atribuíram as religiões primitivas" (Vattimo, 2002a, p. 66).

$\mathrm{Na}$ apresentação do dossiê dedicado ao seu pensamento na revista de filosofia A Parte Rei, mais uma vez Gianni Vattimo (2007) explicita sua opção quando afırma:

Agora, eu me interesso quase exclusivamente pela (filosofia) política e pela reflexão religiosa. Não acho que tenha que argumentar a centralidade dessas duas temáticas para a cotidianidade do mundo - tardo-industrial, neo- imperialista, às vezes decididamente apocalíptico. (p. 1)

Para contrapor e dialogar com o pensamento de Gianni Vattimo optamos por recorrer a Newton Aquiles von Zuben.

0 filósofo brasileiro fez a sua formação, da graduação ao doutorado, na Universidade Católica de Louvain, onde sob orientação de Jacques Taminiaux defendeu tese sobre o pensamento de Martin Buber (Zuben, 1970). Ele traduziu para o português duas das obras mais conhecidas de Martin Buber: Eu e tu e Sobre comunidade.

0 pensamento de Martin Buber continua sendo um referencial recorrente das pesquisas de Newton Aquiles Von Zuben e nos últimos anos ele tem revisto e republicado alguns dos seus textos iniciais (Zuben, 2003; 2008).

Na Universidade Católica de Louvain ele pesquisou nos Arquivos Husserl e foi aluno de Jean Ladrière, Jacques Schotte, Antoine Vergote, Alphonse De Waelhens e outros expoentes do pensamento fenomenológico, como Maurice Merleau-Ponty, Paul Ricoeur e Emmanuel Lèvinas.

Ao voltar ao Brasil, Newton Aquiles von Zuben foi um dos professores fundadores do Programa de Pós-Graduação em História e Filosofia da Educação na Pontifica Universidade Católica de São Paulo. Foi também professor fundador dos programas de Pós-Graduação em Educação da Universidade Metodista de Piracicaba e da Universidade Estadual de Campinas, sendo que nesta última se aposentou como professor titular de Filosofia da Educação.

Nos últimos anos, tem dado continuidade ao seu trabalho de pesquisador e de professor na Pontifícia Universidade Católica de Campinas, dedicando-se exclusivamente à bioética. Entre suas referências teóricas atuais mais constantes encontrase o renomado filósofo da tecnociência Gilbert Hottois, professor da Universidade Livre de Bruxelas.

Ao contrário do intenso ativismo político do filósofo italiano, Newton Aquiles von Zuben tem uma atuação que podemos considerar essencialmente acadêmica.

Embora de formação cristã (foi seminarista na adolescência e foi a partir dessa opção religiosa que foi estudar na Universidade Católica de Louvain), von Zuben se declara agnóstico.

Não tendo uma atividade política militante, na qual suas opções e crenças poderiam ser evidenciadas e tornar-se de fácil acesso, ou ainda, estar disponíveis em seus escritos, a informação de que Newton Aquiles von Zuben (2006) é agnóstico foi obtida em encontros públicos (seminários, congressos e simpósios) em que tanto ele como nós participamos.

0 filósofo brasileiro dialoga com o pensamento e autores pós-modernos (inclusive com

1. Essa citação e as seguintes da obra de Vattimo em italiano foram por nós traduzidas. 
Gianni Vattimo) e poderia ser considerado um deles, quando, por exemplo, critica a crença no progresso ilimitado da ciência e enfatiza positivamente a pluralidade cultural das sociedades contemporâneas, mas ele não se define como um pensador pós-moderno.

Nos seus textos mais recentes tem dado destaque ao que chama de "racionalidade dialógica", que considera

[...] condição necessária, mas não suficiente, para a efetivação e o desenvolvimento do projeto bioético como nova aproximação da problemática que defrontamos atualmente. Digo "aproximação" atribuindo a esse termo todo o peso epistemológico possível, pois engloba, numa estranha e original articulação, teoria e prática, não se identificando simplesmente com alguma delas em particular; não é visão (teoria) somente, nem é práxis somente, mas aproximação, orientada pela totalidade possível: é convergente, complexificante. (p. 153)

Portanto, é com as contribuições e em diálogo com esses autores que pretendemos analisar como os discursos contemporâneos sobre a natureza incluem interpretações sobre a biodiversidade e sobre os transgênicos ao mesmo tempo que trazem novos desafios à Educação Ambiental.

A noção de biodiversidade é a que mais se aproxima da noção de senso comum de natureza, no seu sentido puramente biológico. Mesmo entre cientistas, como o conceituado biólogo evolucionista Ernest Mayr (2008), a biodiversidade é apresentada como a variação de espécies relacionada com a sistemática que diferencia os organismos e os relacionamentos entre eles.

Outro renomado biólogo evolucionista, Edward O. Wilson (1992), conhecido como um dos precursores da noção de biodiversidade, a relaciona com os aspectos evolutivos das espécies e sua taxonomia.

A biodiversidade é uma noção surgida nas ciências biológicas e que tem tido conside- rável impacto político e ecológico nos últimos anos. Devido a isso, não ficou restrita a essa área de conhecimento e os seus aspectos culturais, sociais e éticos têm sido constantemente discutidos nos meios científicos e de comunicação de massa (cf. González-Gaudiano, 2003; Varella; Fontes; Rocha, 1998).

Estudos antropológicos têm mostrado como que as interações sociais com a natureza provocaram a manipulação técnica, para fins alimentícios ou ritualísticos, de diferentes espécies. Tendo como referência a Amazônia, Eduardo Viveiros de Castro (2002) observa que

[...] boa porção da cobertura vegetal da Amazônia é o resultado de milênios de manipulação humana [...]. Ao contrário do que se imaginaria, aliás, as florestas antropogênicas apresentam maior biodiversidade que as florestas não perturbadas. (p. 326)

Ecólogos que dialogam com a antropologia consideram que a atividade humana amplia a biodiversidade, como observam Keith Brown Jr. e André Victor L. Freitas (2002):

Uma vez reconhecido o fato de que a alta diversidade biológica local pode ser compatível com a presença de atividades humanas ajustadas empiricamente à dinâmica da renovação do sistema, pode-se pesquisar em que medida ela resulta dessas próprias atividades. Ou seja, como certo tipo de uso humano do ambiente contribui para aumentar a diversidade ecológica. (p. 39)

Se levarmos em consideração esses argumentos, não podemos opor a biodiversidade aos transgênicos, pois ambos são originados, em graus diferentes, pela manipulação técnica.

Os estudos acima citados nos desafiam a não definir a biodiversidade como apenas resultado da evolução das espécies e, portanto, essencialmente natural.

Isso nos leva também a não definir os transgênicos como sendo necessariamente o oposto da biodiversidade, ou seja, como "não 
natureza", por estes serem originados de intensa manipulação técnica e em escala industrial.

Considerar o contexto epistemológico, científico, cultural, político e histórico do surgimento e definição dos conceitos nos meios científıcos e a sua posterior difusão, assimilação e uso na sociedade de forma geral é um dos primeiros desafios que se apresentam à Educação Ambiental.

A principal diferenciação que se faz entre biodiversidade e transgênicos e que os coloca em polêmica e antagônica oposição está relacionada com os impactos ecológicos, econômicos, sociais e culturais de cada um.

Podemos apontar aqui outro desafio à Educação Ambiental, que é explicitar as diferenças, similitudes e desafios sociais, culturais e ecológicos existentes entre a biodiversidade e os transgênicos pois ambos apresentam significativas e diferentes intensidades de manipulação científica e industrial, além de componentes estruturais e moleculares originados do processo evolutivo das espécies e/ou introduzidos com o uso de técnicas.

A diferença a ser enfatizada é que na biodiversidade o manuseio técnico que altera a constituição biológica inicial das espécies está pautado nos recursos do patrimônio cultural tradicional de grupos humanos, com baixo impacto ecológico e voltado para a sobrevivência desses grupos.

Em sentido contrário, os transgênicos estão relacionados com o modelo industrial de produção de alimentos e seres vivos, pautados no desenvolvimento cientifico e técnico altamente especializado, e que traz consigo a crença no progresso e na ciência (e de como eles colaboram e ampliam o bem-estar da humanidade).

Os transgênicos estão também relacionados com o aumento da produção e oferta de mercadorias industrializadas, para que sejam consumidas em escala intensiva e possam gerar lucros econômicos não menos intensos.

Podemos aqui apontar um outro desafio à Educação Ambiental, que é discutir a qualidade dos alimentos transgênicos consumidos como opção consciente (ou pela falta de opção) pelos cidadãos e cidadãs; a (in)possibilidade de se produzir alimentos com baixo impacto ambiental para alimentar uma população cada vez mais crescente; a produção, consumo e distribuição de alimentos de qualidade a um maior número de pessoas e não apenas a uma camada da população que procura e pode pagar mais caro por alimentos "naturais “ ou "orgânicos" (cf. Menasche, 2005; Pedrancini et al., 2008; Furnival; Pinheiro, 2008).

Com base na literatura especializada consultada sobre o tema podemos concluir que as controvérsias sobre os impactos ecológicos dos transgênicos dividem opiniões em grupos com características bem claras: os favoráveis a eles geralmente utilizam os argumentos do progresso contínuo e inquestionável da ciência e de sua contribuição incondicional ao desenvolvimento. Os que se situam no grupo dos contrários aos transgênicos alegam a inexistência de estudos e pesquisas cientificas confiáveis que comprovem a eficiência e a ausência de danos ao meio ambiente e às pessoas no uso indiscriminado de uma "natureza produzida em laboratório".

0 terceiro grupo é caracterizado por aqueles que não recusam os transgênicos $a$ priori, mas também não fazem apologia deles com discursos economicistas e/ou cientificistas e clamam pelo "principio de precaução".

É nesse terceiro grupo que encontramos Gianni Vattimo (2006a) e Newton Aquiles von Zuben (2006).

A noção única e definitiva de natureza que fundamenta uma metafísica politicamente totalitária e religiosamente (cristã) fundamentalista é criticada por ambos os autores com os quais dialogamos.

A biodiversidade e os transgênicos têm situado-se como antagônicos na clivagem natural-artificial. Clivagem essa fundamental para a bioética e para a Educação Ambiental, já que estão consolidadas, em diferentes sociedades, as representações que relacionam o natural com o benéfico e o artificial com o maléfico.

Newton Aquiles von Zuben (2006) observa que 
[...] na linguagem comum, o termo "artificial" parece remeter a uma oposição entre "arte" (artefato) e natureza, sendo que a natureza representa o lado bom. 0 que é natural parece representar o bom, o belo, o verdadeiro. 0 artificial designaria o inautêntico, o fabricado, o estranho, o excessivo, enfim, o mau. Por exemplo, o sorriso da aeromoça, a flor de plástico, o telefone celular, a fertilização in vitro, a ovelha Dolly são coisas artificiais. Podemos perguntar de onde surge a constatação de que um produto do trabalho e da arte inventiva da inteligência humana seja objeto de maior estima e valoração? Como explicar o juízo do que é natural ou artificial passe do domínio do gosto para o domínio de conotação moral? (p. 79)

Sobre a referida clivagem entre o natural e o artificial, Gianni Vattimo (2006a) se posiciona nestes termos:

Deixando de lado a hipótese de ficção cientifica fantástica do ditador maluco que se construiu um exército de super-homens clonando um halterofilista qualquer, inteligente e disciplinado (mas não seria mais cômodo e econômico o adestramento de marines sobre os quais ninguém tem nada o que falar?), o horror com o qual se relaciona a possibilidade de clonagem deveria ser profundamente redimensionado se, no lugar de uma concepção rígida do que é natureza e do que não é, colocássemos no lugar a ideia de que a moral é uma questão de livre e informado consentimento entre sujeitos racionais. 0 que não significa sujeito "abstrato”, privado de história, de crença, de hábitos de vida, de tradição cultural. (p. 12)

Esses questionamentos remetem à análise para o que se entende por mundo natural e, consequentemente, ao que se entende por natureza e por vida. Para Vattimo e von Zuben esses entendimentos ainda estão carregados de tradições morais e religiosas, dogmáticas e totalitárias.

Eles afirmam em diferentes momentos que as inter-relações das noções de mundo natural, natureza e vida e o conflito de interpretações sobre elas influenciam o debate sobre a importância (ou não) da manipulação técnica (da natureza e da vida), assim como evidenciam a influência de dogmas religiosos nas decisões políticas e pessoais relacionadas com, entre outros temas, fertilização, política demográfica, aborto, livre-arbítrio, eutanásia e "qualidade de vida".

Identificamos aqui outro desafio à Educação Ambiental que é abordar essas questões sem recorrer aos dogmas religiosos e ideológicos e nem ao conhecimento de senso comum, difundido principalmente pelos meios de comunicação de massa (Menasche, 2005).

Consideramos que o desafio maior que se nos apresenta é o de considerar a presença dos dogmas religiosos e ideológicos na vida cotidiana e possibilitar a sua discussão e possível superação nas práticas pedagógicas de Educação Ambiental.

Nossos autores não ficam restritos apenas aos questionamentos bioéticos provocados pela clivagem natural-artificial incluindo-a em sua dimensão cultural e política, pois nascer, viver e morrer com dignidade são direitos a serem conquistados por grandes parcelas de cidadãos e cidadãs de nossa época.

Para o filósofo brasileiro,

[...] o mundo humano está sendo desorganizado e reorganizado na sua dimensão biológica (Henri Atlan, com sua teoria da auto-organização e Varela e Maturama com a ideia de autopoiese), com a manipulação genética; e na sua dimensão psíquica, com o controle da personalidade e o paroxismo informático (as conquistas da neurociência e da cibernética com "novos modos de compreender"). De outro lado, parece que o objetivo de muitos é buscar um retorno à essência humana ou à natureza humana, conceitos de coloração metafísica, quando no entender de diversos filósofos a metafísica estaria desconstruída. Verifico, com certa apreensão, que tal retorno teria por finalidade, considerando a "essência", como um parâmetro imutável, 
estabelecer limites às mais variadas intervenções tecnocientíficas e a seus "possíveis". (Zuben, 2006, p. 142)

Gianni Vattimo (2006a) afirma ser daqueles que consideram necessário assumir um conceito de vida que não seja puramente biológico e que procura um outro, mais orientado sobre valores mais autênticos; ele cita um exemplo:

Não há sentido numa política demográfica que impede a contracepção [...]. Não há sentido em defender o direito de qualquer conceito de vida sem considerar quais são as suas possibilidades concretas de ter uma vida 'digna de ser vivida' [...] contra o direito incondicional da vida - que muitas e tão veneráveis instituições, que hoje a reivindicam, foram tranquilamente superadas no século passado, quando teorizavam sobre a guerra justa e o lícito da pena de morte - deveríamos hoje reivindicar a vida no direito. A vida humana, argumento um pouco mais radicalmente, começa quando nasce um sujeito capaz de reivindicar direitos e de cumprir deveres. (p. 34)

$\mathrm{Na}$ análise da clivagem natural-artificial, tendo Gianni Vattimo e Newton Aquiles von Zuben como interlocutores, não é possível se restringir à biodiversidade e/ou aos transgênicos.

Se esses dois temas e a sua complexa problemática correlata desafiam a Educação Ambiental, também o fazem os outros relacionados com a clivagem natural-artificial, como os apontados pelos autores.

Não seria incorreto afirmar que a biodiversidade, entendida como natureza "não manipulada tecnicamente” está relacionada com a origem da Educação Ambiental e nela continuará presente, no entanto, entre os desafios que se apresentam à Educação Ambiental contemporânea está o de ultrapassar os aspectos puramente biológicos (evolutivos) da biodiversidade e incorporar os seus aspectos antropológicos, culturais, econômicos e políticos.

Em relação aos transgênicos entendemos que o desafio que se apresenta está relacionado com as dificuldades teóricas e políticas de se analisar com profundidade as consequências sociais, políticas, culturais, éticas e ecológicas dos derivados da manipulação técnica da natureza (e da vida) em grande escala industrial. Como já foi observado, na clivagem entre o natural e o artificial encontram-se complexas questões morais que caracterizam e definem, bem ou mal, crenças e tradições religiosas milenares, assim como crenças laicas originadas na modernidade como a fé incondicional nos benefícios da ciência e no progresso que ela nos proporciona.

0 pensamento ecologista, como uma das vertentes do pós-modernismo, colocou em xeque as crenças laicas relacionadas com o progresso industrial e científico, como as inerentes à melhoria da qualidade de vida da população. Esse pensamento se constituiu a partir da critica radical que fez da herança moderna e positivista da crença no "progresso pela ciência”. Porém, essa critica não pode ser confundida com um camuflado discurso contrário a toda e qualquer ciência. Ela teve o mérito e a audácia de tocar em crenças que se consolidavam e se aproximavam de dogmas. Laicos é verdade, mas ainda assim com a força dos dogmas na comunidade científica em geral, na educação e nos meios de comunicação e de difusão das "contribuições da ciência” ao grande público.

A critica radical a esse predomínio e hegemonia do elogio incondicional à ciência, elaborada em discursos filosóficos, literários e artísticos, marcou época no debate ético, cultural, científico e político na segunda metade do século XX.

No entanto, em relação com os dogmas religiosos, uma vertente do pensamento ecologista, também pós-moderna, que reivindica "espiritualidade", tem tido uma relação ambígua com a ciência.

Não faltam nessa vertente argumentos que misturam: física quântica com budismo; conhecimentos étnicos e rituais religiosos tradicionais com o reformismo capitalista do desenvolvimento sustentável; princípios do 
cristianismo com a noção de Pachamama ("Mãe Terra") e com rápidas interpretações da teoria da complexidade; mitologia grega para definir a Terra como organismo vivo que se autoorganiza com apologias à energia nuclear.

Os questionamentos éticos, políticos e ecológicos apresentados por Gianni Vattimo e Newton Aquiles von Zuben, por meio dos seus textos filosóficos relacionados com a bioética não são distantes nem diferentes dos questionamentos da Educação Ambiental - pelo menos na sua vertente mais critica e política, influenciada de uma forma ou de outra pelo pensamento radical e pós-moderno dos autores, escritores e ativistas contrários aos dogmas laicos e religiosos - que pode ser encontrada em várias partes do mundo e notadamente na América Latina (cf. González-Gaudiano; Peters, 2008, GonzálezGaudiano, 2007; Pelicioni; Philippi Junior, 2007; Tozoni-Reis, 2004; Noal; Barcelos, 2003; Reigota, 1999; Rodrigues, 1997; Heemann, 1993).

0 que podemos apontar como sendo uma diferença significativa neste momento histórico entre a bioética e a Educação Ambiental é que a primeira se desenvolveu a partir das análises sobre as manipulações técnicas e cientificas do patrimônio genético das espécies, inclusive dos seres humanos, e que a segunda se desenvolveu com as análises das relações políticas entre a natureza, a sociedade e a cultura.

A biodiversidade (em outros tempos considerada e definida como "recurso natural") ocupa posição privilegiada na Educação Ambiental. Ao dar continuidade à sua tradição, romper com os seus limites naturalistas e ampliar suas possibilidades, incluindo os componentes éticos, políticos e culturais, trará uma renovação não apenas temática, mas, também, conceitual. Esse movimento já pode ser identificado em alguns autores (cf. Costa-Neto, 2003; Falchetti; Caravita, 2004; González-Gaudiano, 2003).

Ao contrário da bioética, a Educação Ambiental, não desenvolveu até o momento, ou pelo menos ainda não identificamos nas nossas pesquisas, argumentos e reflexões específicas, ou seja, argumentos teóricos consistentes e in- fluentes, sobre a "natureza artificial" na e da vida contemporânea.

Em relação aos transgênicos e, consequentemente, à manipulação em escala industrial das espécies e da vida como mercadorias para consumo e objetos de desejo em sociedades que têm nas tecnociências o elemento mais importante do modelo de desenvolvimento econômico capitalista, dificilmente se encontrará na tradição critica latino-americana da Educação Ambiental qualquer apologia a eles. Porém, um outro desafio que se apresenta à Educação Ambiental é como incluir essa temática contemporânea e controversa (presente na vida cotidiana de grupos sociais e pessoas de diferentes níveis econômicos, de escolaridade e de participação política) nas práticas pedagógicas de forma consistente, responsável, autônoma e independente.

Nesse sentido, a possibilidade e a necessidade de diálogos mais estreitos e constantes da Educação Ambiental com a bioética tendem a se ampliar.

Mesmo não sendo o foco central da reflexão de Gianni Vattimo e Newton Aquiles von Zubem, como já foi observado, eles abordam as consequências ecológicas das manipulações técnicas. Alguns dos seus argumentos poderiam ser facilmente identificados com os discursos que iniciaram e deram continuidade à Educação Ambiental com as características acima mencionadas.

0 filósofo italiano escreve:

Hoje, poucos de nós colocam em dúvida os resultados da ciência; a olhamos com prudência e justa desconfiança quando - como é cada vez mais frequente - se mistura com os grandes poderes econômicos, públicos ou privados, de cujo sustento necessita para desenvolver-se. Certo, os organismos geneticamente modificados comportam riscos porque podem produzir alterações irreversíveis e não previstas em plantas comestiveis essenciais para nós. Assim firmamos o principio de precaução. Mas aqueles que os hostilizam estão muito mais preocupados com o poder que as novas patentes darão às grandes indústrias, 
interessadas apenas no lucro de seus acionistas. (Vattimo, 2006a, p. 132)

Em outra passagem, sobre a Conferência das Nações Unidas para o Desenvolvimento Sustentado, a Rio+10, ocorrida em Johanesburgo em 2002, ele escreve:

Ao se ler com atenção o inventário dos problemas de que se fala em Johannesburgo, e, por exemplo, se colocarmos juntos os desastres ambientais com a epidemia da Aids, da malária, da tuberculose, se percebe que uma confiança qualquer na técnica devemos ter. Se poderá dizer que serão limitadas as emissões de dióxido de carbono; mas queremos também que a industria farmacêutica produza mais remédios contra a Aids e a preços mais baixos, pois é difícil pensar que a epidemia (mesmo que tenha sido resultado de um erro biológico, ou das experiências em laboratório de um louco), possa ser vencida somente com o retorno a condições gerais de vida mais próximas da "natureza' e menos sujeita à $h y$ bris à vontade duvidosa da técnica. (p. 92)

Os argumentos de Newton Aquiles von Zuben (2006), são complementares aos de Gianni Vattimo e vice-versa. 0 filósofo brasileiro afirma que:

Qualquer consideração sobre o legado herdado da ciência moderna, vale dizer, a tecnociência, e sobre o modo como condiciona a vida social do homem contemporâneo e as implicações de novos paradigmas ou matrizes epistêmicas ou ético-valorativas a serem reinventados pelo individuo, deve, a meu ver, evitar dois extremos, que são na realidade, duas ciladas: a ilusão otimista cultivada até a metade do século 20 segundo a qual tudo o que tem sido alcançado pela ciência e pela tecnologia é identificado com o progresso, e em segundo lugar a proposta, também ilusória, de uma "volta à natureza" como solução para todos os males. Aliás, essa última posi- ção se esquece, penso eu, de que não há natureza pura; e ainda, afinal, por que a natureza deveria conter totalmente o bem? (p. 110)

Em outra passagem Newton Aquiles von Zuben (2006) escreve:

As tecnociências tem, de fato, proporcionado inequívoca melhora nas nossas condições de vida ao prolongar a longevidade ou a expectativa de vida, ao aperfeiçoar a qualidade de vida de um número cada vez maior de indivíduos, e ao modificar as relações humanas. Por outro lado, são tributárias de um aumento crescente de graves problemas e sérios riscos, tanto para a saúde dos indivíduos quanto para o meio ambiente do planeta. E, sobretudo, o que é mais danoso para a humanidade, as tecnociências têm provocado um indecente processo de exclusão de uma parte considerável da humanidade para a qual tais inovações tecnocientíficas não são acessiveis por seu alto custo financeiro. (p. 41)

Esses argumentos, entre vários outros que poderiam ser aqui explicitados, mostram a proximidade dos dois autores, mas eles se diferenciam quanto ao posicionamento político. Situam-se em campos próximos, mas opostos. Não foram até o momento encontrados registros nos quais Newton Aquiles von Zuben tenha se proclamado como um comunista ou que tenha feito elogios ao regime cubano como Gianni Vattimo tem feito (Vattimo, 2006b), mas os dois têm em comum o fato de criticarem a negativa influência do pensamento religioso fundamentalista na definição de políticas, leis e comportamentos.

Eles concordam, politicamente, em vários momentos, sendo que o principal deles, no nosso ponto de vista, é a de considerarem que a laicidade é de fundamental importância numa sociedade democrática.

As tecnociências trouxeram para o debate ético, político e pedagógico os atos de nascer, respirar, alimentar-se, vestir-se, reproduzir-se e morrer. 
No tempo histórico em que vivemos essas questões, outrora tão "naturais", desafiam as instâncias e instituições de normatividade política, legislativa, cultural e educacional a se (re)posicionarem num

contexto de multiculturalidade e de pluralidade ideológica e do reconhecimento, talvez tardio, da multidimensionalidade da realidade em que tem se desenvolvido a existência dos homens. (Zuben, 2006, p. 115)

Em diferentes momentos vimos como os argumentos dos dois filósofos são complementares, mas aqui aparece uma diferença significativa entre eles. Ao contrário da "existência dos homens", do filósofo brasileiro, Gianni Vattimo insiste nas especificidades e diferenças trazidas pelas pessoas e grupos que vivem à margem da sociedade e reivindicam participação e reconhecimento, enfım, cidadania, na diferença. Para Vattimo, eles não são apenas homens, são também mulheres, gays, imigrantes, toxicômanos/as, prostitutas/os, alcoólatras, pobres, feios/as, sujos/as e malditos/as.

Nesse sentido a discussão sobre cidadania, dimensão política cara à Educação Ambiental, aparece de forma implícita e é reafirmada a sua importância na consolidação de uma sociedade multicultural e democrática. Observa Vattimo (2006a) que:

Com liberdade de opinião, de imprensa, de religião, enfım o 'direito de liberdade' que tem sido validado inclusive com a contribuição dos fiéis, mas muitas vezes contra as posições oficiais da igreja - tornou-se extremamente complexa e pluralista. E o pluralismo moderno, que certamente traz tantas vantagens, tem também o preço de ter afırmado, pelo menos em principio, a liberdade da consciência individual de todos os indivíduos em iguais condições. (p. 23)

\section{Para Newton Aquiles von Zuben (2006):}

Parece não haver acordo sobre princípios fundamentais, uma vez que o pluralismo cultural, ideológico, filosófico, político e religioso impõese hoje de modo irreversível. Do mesmo modo a diversidade e a complexidade de nossas sociedades exigem novos modos de relação social. Por outro lado, o caráter problemático (no sentido filosófico do termo) das realizações do projeto tecnocientífico revela de modo dramático a fragilidade e a ambiguidade da condição humana. Isso torna imperativa a tomada de decisão, por vezes imediata e urgente. A solução de caráter pragmático, sem dúvida, cujo principio regulador é a racionalidade dialógica, seria responsável pelo único consenso esperado, isto é, a possibilidade da palavra acordada a cada um, permitindo a participação livre e igualitária e o confronto das mais diferentes perspectivas. (p. 152)

A extensiva exposição dos argumentos, esmiuçados e repetidos por Gianni Vattimo e Newton Aquiles von Zuben nas obras consultadas, sobre ética, metafísica, laicidade, diversidade cultural, pluralismo político e suas relações com a clivagem contemporânea entre o "natural" e o "artificial" nos direciona para o papel da educação (ambiental) nesse contexto.

Até onde conhecemos da obra de Gianni Vattimo podemos dizer que ele pouco escreveu sobre educação; no entanto, um dos seus primeiros textos publicados no Brasil trata exatamente sobre o tema.

No artigo "A educação contemporânea entre a epistemologia e a hermenêutica” Gianni Vattimo dialoga com o texto Einleitung in die geisteswissenschaften, de Wilhelm Dilthey, publicado em 1884, que afirmava a necessidade de uma formação ampla das classes dirigentes, e Vattimo (1992) observa que:

[...] a nós parece evidente que a necessidade de uma visão global do processo social não diz respeito unicamente às classes dirigentes, mas a cada cidadão de uma sociedade democrática. (p. 9)

Em outra passagem do mesmo texto ele escreve: 
Ora, seria ridículo negar a importância da ciência e da técnica em nossas sociedades atuais, mas me parece evidente que a importância fundamental do ideal cientifico da educação foi consideravelmente reduzido. E uma das razões dessa redução é o fato de que, por múltiplas causas, a crença comum no progresso inevitável da história dissolveu-se. (p. 13)

Um livro de Gianni Vattimo com características pedagógicas é Técnica ed esistenza: una mappa filosofica del novecento. Na introdução, o autor avisa que não se trata de um livro escrito para especialistas (filósofos), mas que é introdutório ao influente pensamento filosófico ocidental do século XX, caracterizado pela reflexão sobre a técnica.

0 livro é resultado de um curso que Gianni Vattimo (2002a) deu aos estudantes de engenharia do Instituto Politécnico de Turim. Ele justifica o conteúdo do curso e sua opção temática observando que:

Concentrar-se, como faço aqui, sobre o tema da técnica não foi uma decisão que sai da destinação original do curso aos estudantes de engenharia; responde à convicção (aliás amplamente presente em tantos filósofos hoje) que é esta a "novidade" principal com a qual a existência humana deve medir-se no nosso tempo. (p. x-xi).

Com esse objetivo didático, Gianni Vattimo oferece aos estudantes de engenharia e aos leitores interessados nas abordagens filosóficas sobre a técnica uma panorâmica com pensadores diversos (basicamente europeus, com alguma referência aos norte-americanos), entre eles cineastas, escritores e pintores.

No referido curso foram abordados aspectos que dizem respeito diretamente aos temas que frequentam os argumentos da Educação Ambiental como, por exemplo, os direitos dos animais. Para Gianni Vattimo (2002a):

A questão dos direitos dos animais pode ser considerada como a última consequência da crise da ética. Não somente podemos suspeitar que as nossas ideias morais são somente ideias próprias de uma cultura histórica determinada; mas pode ser que são somente ideias de uma espécie animal determinada, que sempre dominou o planeta e que considerou óbvio, por exemplo, que os cães, os macacos etc., não são titulares de direitos. (p. 92)

Pela sua trajetória profissional, Newton Aquiles von Zuben durante muitos anos direcionou a sua reflexão à filosofia da educação. Juntamente com os seus colegas brasileiros na Universidade Católica de Louvain, Antonio Muniz de Rezende e Antonio Joaquim Severino, teve papel destacado no desenvolvimento da perspectiva educacional fenomenológica no Brasil (cf. Rezende, 1990; Severino, 1983; Zuben, 1984).

Concentrando seus trabalhos pedagógicos no pensamento de Martin Buber (Zuben, $1984 ; 2003$; 2008), principalmente na noção e importância do diálogo nas relações entre os diferentes, o filósofo brasileiro trouxe contribuições fundamentais para a educação em geral e para a Educação Ambiental voltada para a consolidação de uma sociedade democrática e sustentável.

Um dos principais aspectos pedagógicos da Educação Ambiental é justamente o diálogo entre indivíduos em posições diferenciadas no processo e abertos ao "outro", ao diferente, aos seus conhecimentos, representações, questionamentos e possibilidades. No entanto, essa postura ética e política pode banalizar o processo pedagógico. Newton Aquiles von Zuben (2003), nos alerta que, para Martin Buber, o diálogo, não era uma

[...] mera categoria de um humanismo piegas e anacrônico, ou então definindo-o como simples processo a ser estudado pela teoria da comunicação ou pela psicologia... o diálogo foi para ele o elemento propulsor e catalisador de toda a sua concepção de homem, de sociedade, educação, religião, terapia etc. (p. 165-166)

A contribuição à Educação (Ambiental) de Newton Aquiles von Zuben (2003) se amplia 
e se especifica em dois outros trechos. 0 primeiro deles é mais uma de suas interpretações sobre o pensamento de Martin Buber, na qual ele observa que:

0 homem, para além de suas necessidades vitais pode, e somente ele, ver o mundo, não como um Umwelt, mas como uma totalidade. Somente o homem pode substituir o conglomerado sem significado pela unidade daquilo que chamamos "mundo". 0 homem existe em relação ao mundo e o mundo por sua vez só existe pelo homem. 0 animal depende do mundo; ele está determinado, de maneira absoluta, por aquilo que o cerca. Se o homem, de certa maneira, é determinado pelo mundo, ele pode também determiná-lo, e essa determinação ele a experimenta como intimamente ligada à sua liberdade. (p. 117-118)

O segundo trecho selecionado de sua obra nos permite considerá-lo como a síntese do próprio pensamento político-pedagógico de Newton Aquiles von Zuben (2006). Isso se dá quando ele escreve:

Ora, se o bem comum interessa a todo o mundo, o progresso significa permitir ao individuo comum levantar, com transparência, certas questões-chave para o futuro de nossas sociedades, tais como: como confrontar as conquistas da cidadania democrática com os avanços tecnocientíficos? Que valores determinam as escolhas tecnológicas? Que providências as autoridades públicas estão tomando no sentido de favorecer a uma pluralidade de opções disponiveis, e, em segundo lugar, propiciar a todos os indivíduos da sociedade o conhecimento dessas opções? Em que situações irreversíveis nossa sociedade se engaja no campo energético e da agricultura, por exemplo, deixando even- tualmente um legado não gerenciável para as gerações futuras? (p. 113-114)

Diante do exposto até aqui, chegou o momento de re (situar) a própria Educação Ambiental por meio de duas questões específicas que se respondidas pelos colegas interessados em participar de um debate político e teórico poderão auxiliar na formação de educadores e educadoras ambientais comprometidos em ampliar a pertinência política, social, cultural e pedagógica de suas atividades e intervenções. São elas:

1) Como a Educação Ambiental pode colaborar com a formação dos cidadãos e das cidadãs para participarem dos debates públicos e exercitar seus direitos políticos face aos desafios que nos apresentam a biodiversidade e os transgênicos?

2) Como a Educação Ambiental poderá contribuir para que os cidadãos e cidadãs ampliem sua compreensão da clivagem entre o natural e o artificial e a partir daí terem uma intervenção (coletiva e/ou individual) pública e cotidiana, pautada em conhecimentos ou pelo menos em representações, contrárias ou favoráveis, mais sólidas, sobre uns e outros?

Da possibilidade de os cidadãos e cidadãs apresentarem argumentos pertinentes, legítimos e pautados em conhecimentos originados de aprofundados debates públicos e processos pedagógicos dialógicos e não dogmáticos muito dependerá a continuidade da trajetória da Educação Ambiental voltada para a construção de uma sociedade sustentável, justa, livre e democrática. Os encontros e diálogos da Educação Ambiental com a bioética poderão ampliar as possibilidades de intervenção e pertinência de ambas. Nesse sentido consideramos que as obras de Gianni Vattimo e Newton Aquiles von Zuben são um convite, um alento e incontornáveis. 


\section{Referências bibliográficas}

BROWN JUNIOR, K.; FREITAS, A. V. L. Diversidade ecológica no Alto Juruá: avaliação, causas e manutenção. In: CUNHA, M. C.; ALMEIDA, M. B. (Orgs.). Enciclopédia da floresta - o Alto Juruá: Práticas e conhecimentos das populações. São Paulo: Companhia das Letras, 2002. p. 33-42

CASCINO, F.; JACOBI, P.; OLIVEIRA, J. F. (Orgs.). Educação, meio ambiente e cidadania: reflexões e experiências. São Paulo: Secretaria do Meio Ambiente, 1998.

CASTRO, E. V. A inconstância da alma selvagem e outros ensaios de antropologia. São Paulo: Cosac Naify, 2002.

COSTA-NETO, E. Etnoentomologia no povoado de Pedra Branca, município de Santa Terezinha, Bahia: um estudo de caso das interações seres humanos/insetos. 2003. Tese (Doutorado)- Universidade Federal de São Carlos, São Carlos. 2003.

DERRIDA, J.; VATTIMO, G. (Orgs.). A religião. Tradução Guilherme João de Freitas Teixeira, Roberta Barni, Cláudia Cavalcanti e Tadeu Mazzola Verza. São Paulo: Estação Liberdade, 2000.

FALCHETTI, E.; CARAVITA S. (Orgs.). A scuola di animali: pensieri a confronto per un nuovo rapporto. Roma: Franco Muzzio, 2004.

FURNIVAL, A. C.; PINHEIRO, S. M. A percepção pública da informação sobre os potencias riscos dos transgênicos na cadeia alimentar. História, Ciências, Saúde: Manguinhos, v. 15. n. 2, p. 277-291, 2008.

GIRARD, R.; VATTIMO, G. Christianisme et modernité. Tradução Renaud Temperini. Paris: Flammarion, 2009.

GONZÁLEZ-GAUDIANO, E. Educación para la biodiversidad. Revista Água y Desarollo Sustenable, México, v.1, n. 4, p. 1-3, jun. 2003.

. La educación frente al desafio ambiental global: una visión latinoamericana. México: Crefal/Plaza y Valdes, 2007.

; PETERS, M. A. (Eds.). Environmental education: identity, politics and citizenship. Rotterdan/Tapei: Sense, 2008.

HEEMANN, A. Natureza e ética: dilemas e perspectivas educacionais. Curitiba: Editora da UFPR, 1993.

MAYR, E. Isto é biologia: a ciência do mundo vivo. Tradução Cláudio Ângelo. São Paulo: Companhia das Letras, 2008.

MENASCHE, R. Os grãos da discórdia e o trabalho da mídia. Opinião Pública (online), v. 11, n. 1. p. 169-191, 2005.

NOAL, F.; BARCELOS, V. (Orgs.). Educação ambiental e cidadania: cenários brasileiros. Santa Cruz do Sul: Edunisc, 2003.

ODA, T. Janelas e tempo. São Paulo: Escrituras, 2003.

PEDRANCINI, V. D. et al. Saber científico e conhecimento espontâneo: opiniões de alunos do ensino médio sobre transgênicos.

Ciência e Educação, v. 14, n. 1, p. 135-146, 2008.

PELICIONI, M. C. F.; PHILIPPI JUNIOR, A. (Orgs.). Educação ambiental em diferentes espaços. São Paulo: Signus/Nisam/USP, 2007.

REIGOTA, M. A floresta e a escola: por uma educação ambiental pós-moderna. São Paulo: Cortez, 1999.

REZENDE, A. M. Concepção fenomenológica da educação. São Paulo: Cortez, 1990.

RODRIGUES, V. (Org.). Muda o mundo, Raimundo! Educação ambiental no ensino básico. Brasília/Rio de Janeiro: WWF/MMA Fundação Roberto Marinho, 1997.

RORTY, R.; VATTIMO, G. Il futuro della religione: Solidarietà, carità ironia. Milano: Garzanti, 2005.

SEVERINO, A. J. Pessoa e existência: iniciação ao personalismo de Emmanuel Mournier. São Paulo: Cortez, 1983.

TOZONI-REIS, M. Educação ambiental: natureza, razão e história. Campinas: Autores Associados, 2004. 
VARELLA, M. D.; FONTES, E.; ROCHA, F. G.. Biosegurança e biodiversidade: contexto científico e regulamentar. Belo Horizonte: Del Rey, 1998.

VATTIMO, G. A educação contemporânea entre a epistemologia e a hermenêutica. Tempo Brasileiro, Rio de Janeiro, n. 108, p. 9-18, jan./mar. 1992.

Tecnica ed esistenza: una mappa filosofica del novecento. Milano: Mondadori, 2002a.

0 fim da modernidade: nililismo e hermenêutica na cultura pós-moderna. Tradução Eduardo Brandão. São Paulo: Martins Fontes, 2002b.

PATERLINI, P. Non essere Dio: un'autobiografia a quattro mani. Régio Emilia: Aliberti, 2006.

La vita dell'altro: bioetica senza metafísica. Lungro di Cosenza: Marco, 2006a.

Ecce comu. La Habana: Instituto Cubano del Livro, 2006b.

0 pensamento dos fracos. Tradução Carina Barres. A Parte Rei, n. 54, p. 1-2 nov. 2007.

. 0 capitalismo é, em grande parte, responsável pela infelicidade (entrevista). Tradução Daniel Costa. Cult, São Paulo, n. 126, ano 11, p. 12-15. 2008.

WILSON, E. O. The diversity of life. London: Allen Lane/The Penguin Press, 1992.

ZABALA, S. Introduction: Gianni Vattimo and weak philosopphy. Weaking philosophy: essays in honour of Gianni Vattimo. Montreal/ Kingston/London/thaca: McGill-Queens's University Press, 2007. p. 1-35.

ZUBEN, N. A. von. La relation chez Martin Buber. 1970. Tese (Doutorado)- Université Catholique de Louvain, Louvain. 1970.

Diálogo e existência no pensamento de Buber. In: FORCHIERI, Y. C. Fenomenologia e psicologia. São Paulo: Cortez, 1984. p. 71-85.

Martin Buber: cumplicidade e diálogo. Bauru: Edusc, 2003.

Bioética e tecnociências: a saga de Prometeu e a esperança paradoxal. Bauru: Edusc, 2006.

A questão do inter-humano: uma releitura de Eu e Tu de Martin Buber. Sintese, v. 35, n. 311, p. 87-110, 2008.

Recebido em 03.06.09

Aprovado em 04.05.10

Marcos Reigota é doutor pela Universidade Católica de Louvain, pós-doutorado pela Universidade de Genebra. Pesquisador do CNPq - Nível 2. Editor da Revista de Estudos Universitários. 